\title{
Normative Reconstruction and the Hermeneutics of Recognition ${ }^{1}$
}

Radu Neculau ${ }^{2}$

\begin{abstract}
Axel Honneth's method of normative reconstruction works by verifying the motivational power of our orienting values, confirming the expressive capacity of practical norms with respect to these values, and sanctioning the adequacy of social institutions to their guiding norms. This paper examines these functions against the conceptual background provided by the notion of recognition as an interpretive practice and in contrast to two theoretical alternatives: Charles Taylor's account of practical reasoning as reasoning in transitions and Paul Ricoeur's conception of ideology critique.
\end{abstract}

Key Words: Normative reconstruction. Recognition. Hermeneutics. Axel Honneth. Paul Ricoeur. Charles Taylor.

\section{Reconstrução normativa e a hermenêutica do reconhecimento}

Resumo: O método da reconstrução normativa de Axel Honneth opera mediante a verificação do poder motivacional de nossos valores orientadores, a confirmação da capacidade expressiva das normas práticas com respeito a estes valores, e a sanção da adequação de instituições sociais às normas que as guiam. Este artigo examina estas funções tendo como pano de fundo conceitual a noção de reconhecimento enquanto prática interpretativa e em contraste com duas alternativas teóricas: a abordagem de Charles Taylor do raciocínio prático como raciocínio de transições e a concepção de crítica da ideologia de Paul Ricoeur.

Palavras-chave: Reconstrução normativa. Reconhecimento. Hermenêutica. Axel Honneth. Paul Ricoeur. Charles Taylor.

\footnotetext{
${ }^{1}$ Received on 26/09/2016 and accepted for publication on 01/12/2016.

${ }^{2}$ Associate Professor at the Department of Philosophy, University of Windsor, Canada. E-mail: neculau@uwindsor.ca.
} 
|124 |

Normative Reconstruction...

Reconstrucción normativa y la hermenéutica del reconocimiento

Resumen: El método de reconstrucción normativa de Axel Honneth funciona mediante la verificación del poder motivador de nuestros valores orientadores, la confirmación de la capacidad expresiva de las normas prácticas con relación a estos valores y la sanción de la adecuación de las instituciones sociales respecto a sus normas rectoras. Este artículo examina estas funciones frente a la base conceptual brindada por la noción de reconocimiento como práctica interpretativa y en contraste con dos alternativas teóricas: la consideración de Charles Taylor del razonamiento práctico como razonamiento en transiciones y la concepción de crítica de la ideología de Paul Ricoeur.

Palabras clave: Reconstrucción normativa. Reconocimiento. Hermenéutica. Axel Honneth. Paul Ricoeur. Charles Taylor.

In Pathologies of Reason, Axel Honneth made the surprising observation that his earlier critical views of Adorno's social philosophy had subsequently been moderated by the realization that

\begin{abstract}
Adorno's analysis of capitalism is [...] not an explanatory theory but a hermeneutic of a failed form of life. The components that [...] point in an explanatory direction, like his psychoanalytic theory or the culture industry thesis, have the sole function of hypothetically explaining the rise of particular modes of action and consciousness. The fundamental object of the analysis, however, is to understand them (HONNETH, 2009, p. 55).
\end{abstract}

In this paper I will argue that a similar judgment may apply to Honneth's own attempt in Freedom's Right to ground a conception of justice in a social analytic of the practices and institutional functions that realize (in rational or deformed ways) the normative potential of modern social life. The strategy adopted is to justify this assertion with reference to Honneth's conception of normative reconstruction and the views on practical reasoning and ideology critique of such hermeneutically inclined authors as Charles Taylor and Paul Ricoeur. 
The argument developed in the present paper is based on two claims. The first claim is that the type of social analysis Honneth employs in Freedom's Right and elsewhere should be understood as an attempt to explain how social groups collectively generate and revise the content of the values that secure the normative reproduction of their society. ${ }^{3}$ Changes in the meaning of a value occur when individuals and groups interpretively test the value's practical instantiations (in the form of norms and institutions that regulate social interaction) against the evaluative background from which they are assumed to have emerged. The interpretation is determined in a battlefield of competing opinions and symbolically structured actions in which opposing individuals and groups fight over the correct understanding of the meaning of the values under which their needs and interests can be satisfied. On this view, Honneth's well-known account of the struggle for recognition, that is, his analysis of the conflict over which status functions should be acknowledged as legitimate based on the current understanding of the norms they are alleged to express, could be represented as a clash over the proper interpretation of the meaning of the values that authorize these norms. By explaining the struggle for recognition as a conflict over value interpretations, Honneth can be seen as describing social practices as implicitly interpretive practices. ${ }^{4}$

3 The value under consideration in Honneth's book is freedom and its expressions and manifestations in the various domains of social interaction that have emerged as a result of the gradual process of rationalization of the modern lifeworld. The present account attributes to Honneth a view of norms as rules of action that express implicit or explicit value orientations in the form of practical instructions on how to realize these orientations in a way that can satisfy value-interpreted needs. In this view, values are foundational with respect to norms but not the other way around.

${ }^{4}$ If this account is correct, and if we accept the view that what we take to be social reality consists of facts embedded in interpretations, we should also feel entitled to assert that the objects of social analysis and the cognitive tools used therein must be seen as necessarily rooted in prior interpretations of the meaning of the values that guide the institution and administration 
$\mid 126$ |

Normative Reconstruction...

The second claim is that Honneth's own account of how such interpretive practices are validated or challenged is influenced by the hermeneutical-pragmatist critique of foundationalism, representationalism, and objectivism in philosophy and social theory. ${ }^{5}$ Apart from a few remarks about the need to free Hegel's social philosophy from its obsolete metaphysical infrastructure, there is little direct evidence of this influence in his published work. However, this insufficiently acknowledged dimension of Honneth's thinking is indirectly but persuasively exemplified by his development of the method of normative reconstruction as a tool for adjudicating claims of justice. This method is presented in systematic but still fairly schematic fashion in the introduction to Freedom's Right (HONNETH, 2014a), a subsequent article entitled The Normativity of Ethical Life (HONNETH, 2014b), and a detailed response to one of his critics in the special issue of the journal Critical Horizons that was dedicated to Honneth's book (HONNETH, 2015). In these texts, Honneth no longer describes the first-level interpretive practices of agents who engage in

of normative statuses. To say that social reality is interpreted or even doubly interpreted is to say that social facts are socially instituted normative statuses (things we take to have a certain significance based on whether and how they respond to or how they satisfy our needs) and our conceptual grasp of the facts we bring about through collective or individually aggregated attitudes of recognition of normative statuses is based on pre-existing horizons of meaning (the linguistically articulated values in terms of which we interpret our needs as legitimate generalizable interests).

${ }^{5}$ Some of the main references are authors such as Heidegger, Gadamer, Ricoeur, and Taylor on the so-called Continental side of the analytic-Continental divide; the later Wittgenstein, Sellars, Quine, and Davidson on the analytic side; and Richard Rorty, Robert Brandom, and, to some extent, Jürgen Habermas, who are intellectually conversant with both philosophical traditions and are therefore able to draw on both. For an eminent account of this problematic and for valuable contributions to the debate, I refer the interested reader to the important work of Richard J. Bernstein (1983), the earliest and perhaps most perceptive biographer of the hermeneutical-pragmatist critique in philosophy and social theory. 
communicative practices of recognition. ${ }^{6}$ Here, normative reconstruction is portrayed as something the critical social analyst does (or ought to do, as both observer and participant), it is the second-level reflective practice of extracting valid principles of social justice from the norms and values agents routinely appeal to whenever they engage in first-level interpretive practices of recognition. The claim in this paper is that a careful examination of Honneth's account of normative reconstruction reveals an endorsement of two major tenets of hermeneutical philosophy: (a) a form of hermeneutically grounded expressive inferentialism whose methodological function is to test the inner consistency of the norms of social interaction with their grounding principles (values) and the norms' instantiations (institutions and social practices); and (b) an explanation of how norms (and the values that are expressed through these norms) are either validated (or legitimized) and thereby reinforced, or critiqued (or de-legitimized) and therefore changed based on transformations in the cognitive and motivational make-up of the agents who engage in practices of interpretation and application.

In the remainder of this paper I pursue these points as follows: First, I introduce and examine the notion of normative reconstruction as Honneth presents it in several of his writings. Second, I make good of the claim that recognition is an interpretive practice from the ground up by examining several structural features that are common to all attitudes of recognition. In a third step, and using the notion of recognition as a conceptual bridge, I discuss what I take to be the hermeneutical dimension of the method of normative reconstruction with respect to the critique of norms and the overcoming of values. Finally, I consider the relative superiority of Honneth's hermeneutic approach against two

\footnotetext{
${ }^{6}$ These practices assume the existence of a basic evaluative consensus around norms and a capacity to reason inferentially from values to their normative implications and reflectively from particular instances to the rules they instantiate. Honneth's challenge in his account of normative reconstruction is to reveal the untapped critical potential of this assumption.
} 
|128 |

Normative Reconstruction...

conceptual alternatives: Charles Taylor's conception of practical reasoning and Paul Ricoeur's account of ideology critique.

\title{
What is normative reconstruction?
}

In Freedom's Right, Honneth discusses this method in the context of his attempt to "implement the normative aims of a theory of justice through social analysis, taking immanently justified values as a criterion for processing and sorting out the empirical material". As he argues,

\begin{abstract}
Given institutions and practices will be analyzed in terms of their normative achievements and recounted in order of their significance for the social embodiment and realization of socially legitimated values. [...] 'Reconstruction' means that out of the entirety of social routines and institutions, we will only pick out those that are indispensable for social reproduction. And because the aims of social reproduction are essentially determined by accepted values, 'normative' reconstruction means categorizing and ordering these routines and institutions according to the impact of their individual contribution to the stabilization and implementation of these values (HONNETH, 2014a, p. 6).
\end{abstract}

This longer quotation seems to suggest that normative reconstruction may consist of two complementary movements or methodological directions of fit, each of which satisfies one of the two main functions of a critical theory of society. The first movement takes the social analyst from the existing values and ideals that determine the form of social reproduction in a society to their empirical actualization in norms and institutions that are essential to the society's reproduction. In this sense, practices that affirm our values and ideals in the social world have the concrete effect of normatively re-shaping it as our world, that is, as an instantiation of what it ought to be according to our ideals and 
values. The other movement captures the theorist's attempt to see if the world we happen to inhabit is, indeed, ours, that is, if its core institutions, norms, and social practices truly match the values they are supposed to embody. The second movement is what allows the theorist to critically assess whether what we take to be an instantiation of our ideals really measures up to the evaluative standards that are implicit in it.

But how does normative reconstruction work and what is involved in it? The conceptual structure of this method is presented in more detail and with greater clarity in The Normativity of Ethical Life. This text, itself a selective recovery of valuable Hegelian ideas, was ostensibly elaborated in response to critics of Freedom's Right who faulted Honneth's ethical immanentism for allegedly erasing the distinction between embracing justified values and enforcing norms of social conformity. Hence, the text focuses on drawing a thicker line of demarcation, within the still immanent horizon of values of a historically given form of life, between what is acceptable to individuals as acculturated members of their social groups and what is also valid, and between their habitual following of existing social rules and their endorsement of norms of action that channel the motivational power of the goods they value. The objective in this text is to determine how the interplay between norms, values, and practices secures the validity of the latter in a limited sense and without assuming, in a circular manner, that which had to be validated in the first place. Needless to say, this distinction is essential for a theory that tries to be both critical and extract its principles from the empirical material of ethical life.

In his paper, Honneth identifies two conditions that together guarantee that a human practice not only is accepted by the members of a group but is also valid. First, using the example of actions we may call free in a Kantian sense of the word, "practices can be candidates for 'ethical life' only if their normative structure gives rise to this sort of freedom". Thus, and generalizing from this example, "human activity counts as a socially realized form of morality not in virtue of being guided by any rules whatsoever but only in virtue of being guided by normative principles that allow 
the participants to mutually view each other both as their authors and as their addressees" (HONNETH, 2014b, p. 819). Moreover, this quality of being both author of and subject to a norm is not something agents exercise by themselves, in isolation from other agents, but rather it is exercised collectively, in a condition of mutual authorization and control of the institution and application of norms that Honneth, following Hegel, calls recognition.

Second, Honneth argues that "the norm itself must be reflective of some ethical value that expresses the intentions and inclinations of each of the agents... collectively accepted norms must be such as to display a certain ethical purpose" (HONNETH, $2014 b$, p. 820-1). While the first condition satisfies the requirement that the institution and application of a norm that regulates a social practice be governed by higher-level norms of mutual recognition (as normative principles), the second condition establishes the validity of a norm depending on whether the value it purportedly expresses resonates with the agents whose actions are normatively regulated in accordance with an interpretation of what that value commands them to do. The norm is valid not just because it is intersubjectively acknowledged as authoritative, but also because participants in a practice regard the values on which the norms or rules of action are based as "conditions of their own self-realization". Hence, "social norms that are objectively valid, in contrast to ones that merely enjoy de facto acceptance, are distinguished both by the fact that they are appealed to as principles for the reciprocal evaluation of actions within a group and by the fact that they express values affirmed by the members of the group" (HONNETH, 2014b, p. 821). If we combine these two conditions, we can safely assert that a practice that is guided by a norm is justified and the norm that regulates it is valid, if agents can regard themselves both as authors and subjects of that norm and as conveyors and competent interpreters of the meaning of the underlying value that the norm is alleged to express.

These two conditions of normative validity spell out in more detail and with greater clarity the relations of mutual determination between values, norms, and actions that the method of normative 
reconstruction tries to conceptually capture for the purpose of critical social analysis. However, there are several other aspects of Honneth's account of normative reconstruction that are worth exploring not only because they further explicate the content of this notion, but also because they highlight its indebtedness to a social philosophy of hermeneutical-pragmatist inspiration. One such aspect concerns the expressive relation between values, norms, and practices that underlies the framework of recognition within which claims of normative validity are decided. The point of discussing this relation is to reveal that it is ultimately interpretive in nature. The other aspect concerns the dialectic of interpretation and application that is at work in recognition and, more specifically, how this dialectic generates changes in the evaluative content of norms, institutions, or practices, and how these in turn change the meaning of the values they are supposed to express. The method of normative reconstruction not only verifies the consistency of a society's normative and institutional arrangements with its underlying evaluative framework, but can also undermine our confidence in that framework itself. By delegitimizing our values, normative reconstruction makes it possible to criticize these values and eventually overcome them.

\section{Recognition as interpretive practice}

What is essential to all conceptions of recognition, including Honneth's, is the idea that normative attitudes institute normative statuses. A normative status is something that can be instituted individually by means of such carriers of normative attitudes as speech acts or other media of symbolization. However, its maintenance or administration requires the collective acknowledgment that it has the claimed significance, or in other words, it requires attitudes of recognition. The general structure of all normative attitudes (and therefore also the structure of recognition) has the following form: taking $\mathrm{X}$ as $\mathrm{Y}$ in context $C$. Here, $X$ could be a feature of the physical or social world that is assigned the special value or normative status $Y$ based on some 
function it fulfills within it. $\mathrm{C}$ is the general horizon of meaning within which an X can be interpreted as a Y. The "as" structure is the structure of symbolization or metaphorization that allows us to move from the realm of natural objects and sentience to the world of meaning and sapience. Most of the time, recognizing involves being able to identify or perceive various features of things (Xs) and then attributing them the right type of normative significance or Y (classifying them "as" statuses) based on what our group or culture (C) attributes such significance to. The "taking" itself is both an intentional act and the practical realization of an intention. Recognition is not just symbolic. When one recognizes a status, one also commits oneself to acting in a particular way that is required by the nature of what is recognized as a valuable feature of our shared world.

All theories that define recognition in this way must start from the insight that the identity of the various entities that make up our natural environment such as chairs and mushrooms is, for the most part, determined by what we, individually and collectively, take them to be, or by what function we, individually and collectively, assign to their substance. The ascription of function is usually based on how a given entity responds to or satisfies some specific needs, for instance, the need for physical support when we take a piece of wood to be a chair or the need to satisfy our hunger when we take a sponge-like fungus to be food. ${ }^{7}$ A piece of wood is taken to be a chair when it satisfies the kind of need that is typically and demonstrably fulfilled by the things we know as chairs, and a fungus is food because it can satisfy hunger the way food stuff does. What makes this theory interesting for social philosophy is that it extends the reach of the insight that normative attitudes determine normative statuses from physical to other kinds of objects, such as abstract entities (concepts or norms) or animated things like persons or souls (ourselves and others).

\footnotetext{
${ }^{7}$ I base this (loosely) on Robert Brandom's account of Hegelian recognition in his influential "The structure of desire and recognition. Self-consciousness and self-constitution" (BRANDOM, 2007).
} 
The identity of the latter, for instance, what we take them to be, is constituted by how they respond to or satisfy an equally specific need or desire, such as a desire to be recognized as having a status that either identifies us as members of a group or distinguishes us from it. ${ }^{8}$ In this case, the need is to some extent physical (its satisfaction or non-satisfaction may involve physical objects and it can generate physiological effects) and to a greater extent socio-psychological (it has psychological effects in addition to the physiological ones and these effects are seen as a product of social interaction). ${ }^{9}$ What is more important, however, is that this new type of need itself has the structure of something we take "as" something (else). It is an instituted status function and we can only make sense of it if we interpret its meaning, what it is (the "as" component), in terms of other things that we value based on their proven ability to help us either satisfy needs or desires or quell them if they cannot be fulfilled. Thus, all theories of recognition that define the attitude of recognition in terms of the notion of "taking" (and these must include Honneth's theory as well) must operate on the assumption that needs and values are interpretively connected in attitudes of recognition of status functions and that norms and institutions are practical tools that help us satisfy needs under a generally accepted interpretation of value.

We can verify this claim by taking a closer look at very simple operations of classification of entities in terms of recognized status functions. When we do so, it is immediately clear that the attitudes of recognition involved in such operations of classification have

\footnotetext{
${ }^{8}$ To provide a simple example of taking that is of some relevance to the present discussion, let us say that the capacity to make decisions autonomously is taken to be a sign of moral and legal responsibility that allows us to recognize the possessor of such a capacity as a legal or moral agent with specific authorities and responsibilities that derive from having such a status.

${ }^{9}$ This distinction between the psychological and the physiological may be hard to maintain empirically.
} 
several, partially overlapping components. ${ }^{10}$ First, there is the cognitive dimension, the identification of status functions, or the subjective attitude of classifying things based on the function they fulfil, such as satisfying existing physical needs. Closely related to it is the attitude of re-identifying a thing as the same in a different context, that is, confirming that it fulfills the same function with respect to the same kind of needs that it did when it was last encountered. ${ }^{11}$

Second, there is an implicit reflective dimension to recognition, which involves the acknowledgment that the cognitive authority we exercise in identifying and re-identifying status functions is social in nature, and that we become aware of it as soon as we start using concepts to classify things. These concepts come with standards of proper application that were not instituted by any individual concept user. Instead, they are based on existing practice, which means that deciding what counts as the successful deployment of a concept in response to a particular instance of an identified function is also not left to the discretion of any individual user. The authorship is collective and the authority to use these concepts is exercised jointly.

This introduces us to a third dimension of recognition, which is the realization that all concept users must share in the capacity to operate with concepts based on publicly available standards of use. To qualify as concept users, agents need to have specific qualities that enable them to identify and re-identify status functions and verify that others can do the same, and these qualities must reflect the nature of the objects of cognition, whether they are features of the natural world or features of the world of values. In the case of

\footnotetext{
${ }^{10}$ They are distinguishable for purposes of analysis only. In practice, they describe different facets of the same phenomenon.

${ }^{11}$ This is the meaning of what Kant calls synthesis of recognition (Rekognition) in the concept in the transcendental deduction section of the first edition of the Critique of Pure Reason. The Kantian notion of recognition is different from Hegelian recognition or Anerkennung, which is an acknowledgment of value and the endorsement of the features that display it.
} 
the latter, recognition involves the capacity to perceive a good that helps us interpret our needs and then attribute this capacity, as an evaluative quality, to the authors and authorized evaluators of our primary attitudes of identification and re-identification. In other words, it assumes a view of agents as ethically competent norm users who are thoroughly acculturated in the evaluative horizon of their communities of reference.

This brief examination of the three dimensions (or structural features) of all attitudes of recognition reveals that our needstructure is thoroughly interpreted; that the interpretation consists of assigning functions that have repeatedly and reliably proven their capacity to satisfy (or repress) needs; that such functions can be described or interpreted in terms of goods or values; that the norms involved in cognizing things "as" having certain functions (the practice of identifying and re-identifying statuses) are subject to the external authority of other competent appraisers; and that these appraisers can perceive the value of the function in terms of which we interpret needs on account of the fact that they also possess the type of qualities that enables them to perceive value and therefore correctly assess how others identify and re-identify functions. In other words, the analysis of recognition in the case of simple operations of classification directly reveals the theoretical grounds of the two main conditions that, according to Honneth, can make a norm valid (and not only socially accepted): they are instituted and maintained collectively, and they express shared value orientations. In addition to this, it demonstrates that the attitude of recognition is interpretive from the ground up and, consequently, that the expressive relations between values, norms, institutions and practices are ultimately a product of the basic interpretive work of assigning meaning based on how instituted status functions satisfy value-interpreted needs. These values are in turn validated intersubjectively by subjects who can recognize each other's capacity to interpret and verify each other's interpretation by appealing to the same evaluative standards. 
|136 |

Normative Reconstruction...

\section{Hermeneutics and normative reconstruction}

As mentioned before, Honneth's social philosophy is implicitly hermeneutical in two ways, with respect to the first level practices of recognition that can be re-described as practices of interpretation, and with respect to the method of normative reconstruction that the analyst uses to sort them out. The account of recognitive practices as interpretive practices that was presented above directly vindicates the first claim. The second claim can be distilled into two components: the requirement that a normative system be expressively coherent, and the requirement that the agents' understanding of the norms be motivated by norm-backing values. The first of these two components can be further explicated as follows: Given that normative reconstruction means testing practices and institutions against norms, and norms against values, and considering that what we test are not dissimilar cognitive contents (representations of the good, rules of action, and actions) but, rather, accounts of the roles each of these contents must play in the wider evaluative context of our recognitive practices, it follows that, when we test the expressive consistency of a normative system that is shaped by attitudes and relations of recognition, we engage in a complex and multilayered process of interpretation that sets out to reconcile the meaning of: (a) the values that are expressed through norms, (b) the formal characteristics of the norms that are supposed to convey the content of these values, and (c) the concrete shape and mode of functioning of the institutions that are set up to carry out the practical intention of norms. ${ }^{12}$

\footnotetext{
12 These various levels also contain specialized and institutionally regulated types of knowledge, such as academic discussions of values, legal analyses of juridical norms, administrative examinations of institutional setups. This specialized knowledge contains explicit rules for verifying that values are clearly articulated, norms consistent with their principles or with other norms, and institutions efficient. But the conclusions reached in each of these areas become elements of the overall process of interpretation that secures the expressive coherence of the normative system.
} 
Earlier I claimed that normative reconstruction involves verifying that such interpretations are consistent with the premises from which they depart, which is to say that the practice of social analysis should be defined as a species of hermeneutically inflected expressive inferentialism (as opposed to verifying the truth of a statement or the rightness of a norm against standards of accuracy or objectivity that are derived from what we take to be the correctly represented social reality or an immediately accessible function of human rationality). Having established the interpretive nature of all norm-instituting attitudes of recognition, I can now further qualify this claim by adding that the "inferences" whose consistency we set out to demonstrate do not contain ground-level variables such as concrete social norms, institutions, or practices, but the interpreted meaning of such variables (what we take to be, or what counts "as", a valid norm, a functioning institution, or an ethical practice) within the wider evaluative context in which they can have significance (or not). These meanings have to be both understood as well as accepted by those to whom the values speak and whose actions are regulated by norms and institutions.

The question of acceptance brings us to the other component of the claim regarding the hermeneutical dimension of normative reconstruction. All the links in the expressive inferential chain that connects values, norms, institutions, and practices have meaning in that they are status functions that must be grounded in motivational relations between agents and the values that shape their needs as legitimate interests. The expressive chain is anchored in motive-generating, value-interpreted needs that close this chain in an interpretive circle. Thus, the second hermeneutical aspect of normative reconstruction will concern the cognitive and motivational effects of norm application, including the changes in the way we interpret the meaning of a norm (or that of a value) when the application fails to yield the expected result.

The issue of failure in application is important in this context because when a norm fails to apply to a new type of action that resists being regulated by that norm, the regulative failure forces us to reconsider the content of that norm itself (HONNETH, 2014b, 
p. 823). This is not a new idea. We know from Heidegger and Gadamer that the dialectic of interpretation and application that is prompted by instances of normative failure can produce significant changes in the content of a norm (HEIDEGGER, 2010, p. 72; GADAMER, 1989, p. 318, 329). What is new in Honneth's explanation is the notion that such changes in the meaning of a norm are triggered by the loss of expressive support from the underlying value, and that, in the absence of radical reinterpretations of the meaning of that norm or value, the original value becomes not only cognitively obsolete in relation to norms, institutions, and practices, but also affectively "faded", unable to motivate and stimulate, or to interpret some needs as legitimate and worth fulfilling (HONNETH, 2014b, p. 824).

The argument introduced here is that interpretation is a function of motivation, and that a motivational deficit will decrease our confidence that a value can resonate with our actual condition and that the matching norm will be seen as meaningful. Ultimately, this also affects how we determine that a norm is valid as opposed to merely accepted. If a value no longer resonates, a non-valid norm will be unable to successfully summon the motivational power of the value it claims to express. What eventually verifies that all these ontologically very different elements - norms, institutions, and practices - are consistent with each other and with their underlying values is whether individuals and groups are ready to accept them as being consistent, which is to say whether they believe (rightly or wrongly) that values resonate with them, that norms truly express values, and that institutions properly convey the authority of norms.

The resistance of an agent to a norm or institution opens up a gap between the actual needs of that agent and the claim that a norm can meet those needs because it expresses the value in terms of which needs are interpreted as legitimate interests. The gap reveals both a deficit in the motivational power of values and norms as well as a cognitive discrepancy between the meaning of a value (or interpretation of value) and the underlying norm. In Honneth's view, normative change in a society is driven by the need to fill in 
this gap with a new norm that better expresses the original value or value-interpretation and therefore better responds to needs. The same reasoning underlies Honneth's defense of the idea of moral progress. Honneth often presents progress as a communal process of self-growth through moral learning that is prompted by struggles over the meaning and content of norms. The notion of progress can be made intelligible in terms of the idea of a cognitive gain that allows us to supply a new norm whenever there is a lag between a newly emerged need and the norm that was originally designed to satisfy it. In this sense, norms are deemed to be better if they closely track changing needs and the values used to interpret them. If we add to this the motivational dimension introduced above, we can perhaps say that normative growth and therefore normative progress can only occur within the temporal interval that is marked by the overlap between value interpreted status functions and the needs they help satisfy. ${ }^{13}$

When needs outrun values, gradual normative progress is replaced by radical evaluative change. Progress with respect to values requires finding a way to show how a new value is superior to the old one. This task is more difficult to prove than demonstrating the superiority of norms. The reason for this is that values, unlike norms, are foundational in Honneth's expressivist scheme. They are self-authenticating or self-validating manifestations of worth and hence not subject to the kind of validation or justification procedures in terms of values and needs to which we typically subject norms. The problem of how to explain a change in values is therefore compounded by the fact that we cannot easily explain the necessity of any such change. Honneth's only possible solution to this problem, to the extent that we can attribute him one, would be to argue that these values are not validated but legitimized, and that they are legitimized by their affective pull, by the feeling of familiarity we experience

${ }^{13}$ The gap can be filled in by a new norm but also by an ideological value interpretation that represses needs instead of satisfying them, and the challenge for Honneth is to find a suitable criterion for distinguishing between them. 
in their presence (which is likely generated by the fact that they are known to reliably satisfy our needs). Values are legitimized when individuals are moved to acknowledge them as appropriate inner reasons for action. Thus, and in a move that goes beyond the hermeneutical context within which it originated, the legitimacy of values or value interpretations will have to be ascertained based exclusively on their motivational capacity. We will say that values or value-interpretations are vindicated when agents are moved to act by their representation. Values lose their motivational power when they are unable to make sense of newly emerged needs. And this is precisely what prompts changes in the meaning of values.

The method of normative reconstruction can explain how a historically unfolding dialectic of interpretation and application that generates normative change can also make values appear ordinary and questionable, thereby eroding our trust in them. When that happens, we stop taking for granted our understanding of ourselves in terms of those values and instead open up to the possibility that our needs are not served by them. Values - just like norms (or Nietzschean metaphors) - start to fade and as a result become less apt at motivating and therefore empowering the wills of those agents who can institute and maintain a normative order. The result of this fading away of the motivational power of a value is the creation of an affective distance between that value and us. It is only from such a distance that we can appreciate that the value in question no longer defines us and that the values we currently favor are superior to those of the past.

We can see how this schema of explanation might work in Honneth's account of ideology, more specifically, his attempt to identify features that could turn the attitude of recognition into an attitude of submission to the normative or evaluative status quo. Honneth introduces as one possible instance of an ideological form of recognition the case of the prewar European male who "freely" submits to the motivational power of a nationalist ideology that promises to deliver him from his social insignificance in exchange for a heroic death on the battlefield (HONNETH, 2008, p. 326). Under what circumstances can we say that his willingness to 
sacrifice himself for the fatherland is an instance of ideological compensation for the pain of a meaningless existence? Honneth's answer is that we can be certain of our judgment that the shopkeeper turned heroic soldier is the victim of an ideology only from the relative safety of our reflective distance from the values of the past that no longer move us (HONNETH, 2008, p. 327). In such cases, Honneth's conception of moral progress across values is in fact wrapped up in a phenomenological account of the objectivizing effect of temporal distance on our endorsement of values as true interpretations of our present needs.

\section{Are there superior alternatives to normative reconstruction?}

This discussion of normative and evaluative change sets the stage for an examination of the ways in which Honneth's hermeneutically inflexed account of normative reconstruction resembles (in theoretical intention) as well as overcomes the limitations of other, in certain respects more elaborate, explanations of normative and evaluative change, namely Charles Taylor's explanation of practical reasoning as reasoning in transitions (TAYLOR, 1995) and Paul Ricoeur's account of ideology critique (RICOEUR, 1986 and 1991). The former provides a very detailed description of normative and evaluative change that goes a long way to clarify some obscure aspects of Honneth's account of moral growth or moral learning. Ricoeur's explanation fills in one important gap in Taylor's conception of reasoning in transitions by presenting the dialectic of two forms of the imagination, ideology and utopia, as the medium in which we test the ultimate motivational power of the values that underwrite our norms of cognition and action.

Taylor presents his conception of practical reasoning as an alternative to what he calls apodictic reasoning. In his view, reasoning in transitions or ad hominem argumentation is a species of comparative argumentation that works without pre-given criteria because the criteria are generated by the comparison itself. Taylor examines this alternative in two different contexts of explanation, 
| 142 |

Normative Reconstruction...

the context of theoretical or scientific explanation and the context of moral argumentation. In each context he analyses two types of transitions, one more radical than the other, which gradually move us away from the model of apodictic reasoning. ${ }^{14}$ The first type of transition consists of providing an interpretation of the world (of nature or of human affairs) that is better at explaining some physical anomalies or moral conflicts than the model it attempts to supersede. The transition is therefore regarded as providing some cognitive gain. Taylor's historical example of such a gain focuses on the transition from the Aristotelian model of explanation of violent motion to the Galilean, which takes into account such physical facts as the gravitational pull of the earth and the force of inertia (TAYLOR, 1995, p. 43-7). Such a transition, Taylor argues, cannot be settled on the apodictic, criterial model of reasoning that claims to settle disputes based on incontestable epistemic principles, for in this model there can be no mediating epistemic principle that could do justice to both theories, and certainly not one that could do so on their own terms. As he argues, one theory looks at final causes and at our place in the moral universe while the other deals with our capacity for model manipulation and efficient control based on reliable prediction. According to Taylor, what we do have is the realization that we can make sense of the transition from the Aristotelian to the Galilean model but not the other way around. This is because the latter can account for both models on its own terms, whereas the former cannot. Thus, even when the two models are ultimately based in different or perhaps incompatible worldviews or systems of value (one governed by the need to figure out one's moral position in the universe, the other by a naturalistic ideal of explanation that has already decided what that position is or that it need not concern itself with such questions), one can move from one to the other without having to decide the transition by appeal to criteria that both models could accept. The transition is a gradual abandonment of one position for another based on the

\footnotetext{
${ }^{14}$ In his article, Taylor (1995) mentions three types of transitions but only two are relevant for the present discussion.
} 
realization that the latter is comparatively "better" on the ground of some "extra-epistemic considerations" (TAYLOR, 1995, p. 46). The new theory or point of view is better because, as Richard Rorty has put it in a similar context of explanation, "they come to seem as better" (RORTY, 1982, p. xxxvii). The judgment involved is comparative, not apodictic. We realize what the superseded position was aiming for, but now we are pursuing something different, which is why we have no choice but to jettison the previous one as comparatively useless. Turning now to moral explanations, a similar type of account could justify the move from, say, an honorbased system of economic activity to a class-based one, and then the move from the ethics that underlies the class-based system to a capacity based ethics that emphasizes the worth of qualities other than lineage or social position. In these cases, we are dealing with a transition that can be described as a gain in moral understanding but only from the standpoint provided by the individualistic ethos that can satisfy the production requirements of the capitalist socioeconomic system. From the perspective of the ancient code of honor, the protestant ethic is incomprehensible.

The second type of transition Taylor discusses illustrates not epistemic gain but rather error-reduction in cases of moral confusion about what values one truly endorses, or about which ones should take precedence in situations of conflict between two sets of values or their instantiation. Taylor's examples deal with situations in which we correct a previous interpretation of our moral situation in relation to our perception of the good. The interpretation in all such cases is a transition that is mediated by a change in our interpretation of that good, or of what the good requires of us. Just like in the previous type of transition, the change that comes to be seen as the correction of an error looks more like a clarification of one's position than a decisive appeal to foundations. In cases of moral clarification, reasoning in transitions means "making appeal to our implicit understanding of our forms of life" (TAYLOR, 1995, p. 49), that is, showing how we stand in relation to values, which values we truly endorse, how we respond to conflicts of value, and 
| 144 |

Normative Reconstruction...

so on. In other words, it means figuring out our position on a given moral map and, in the process, improving on its contents.

When Taylor talks about transitions, he clearly indicates that the justification for moving from one position to another is provided by the transition itself. However, for a transition to qualify as ad hominem argumentation, it would have to also provide the affective grounds for motivating a reasoner to accept the evaluative result of the transition. This, however, cannot be the work of the transition itself, if we understand the transition in strict cognitive terms. The cognitive component is necessary but not sufficient to accept the result of the transition. Understanding a change in the meaning of a norm or value cannot reliably motivate us to also endorse that change. If that were the case, we would never have to explain why agents who are exposed to the explanatory and practical collapse of, say, a political or religious worldview, still cling to it despite all the overwhelming factual and normative evidence that it should be abandoned. This further suggests that the motivational dimension that makes reasoning in transitions an ad hominem form of argumentation must be based in some kind of higher-level consensus, however implicit, on what agents could accept as a common good. Reasoning in transitions can explain normative and evaluative change in terms of cognitive growth or error reduction. However, without showing how changes in the agents' affective attachment to cognitive contents are necessarily linked to error reduction or cognitive growth, it seems unable to fully account for the motivational component of the shifts in the value orientations of a social group. By making it possible to argue that the interplay of interpretation and application not only generates changes in the content or meaning of norms and values, but (by demotivating agents) may also render these values powerless and therefore easier to abandon in favor of other values, Honneth takes one important step beyond the conception of evaluative change that is contained within Taylor's theory of reasoning in transitions.

Unlike Taylor, Ricoeur has a conception of ideology critique that explains normative-evaluative change as a process of 
overcoming motivational deficits. The questions Ricoeur tries to answer in his work on ideology are the following: what happens to the normative thrust of the traditional, Marxist critique of ideology if, in the wake of the hermeneutical-pragmatist turn in philosophy, we discard the epistemological component of ideology (the inverted image that makes it "false") and instead of consciousness and un-interpreted social reality, we refer to, as Ricoeur does (in the language of Clifford Geertz), "belief-systems" and "symbolized structures of action"? What follows if the expressive-causal account of how interests are reproduced in false consciousness is replaced by a Weberian theory of legitimacy deficit? What if the cognitive medium of a theory of representation is abandoned for an evaluative language in which individuals interpret social reality in terms of their orientation toward values (RICOEUR, 1986, p. 14-17, 254-9)? Last but not least, what becomes of the practice of ideology critique itself once we abandon traditional criteria of validation such as truth or normative rightness?

Ricoeur arrives at this own understanding of ideology by means of a regressive analysis of Marx's notion of ideology as distortion of social reality, which leads him to a Weberian understanding of ideology as legitimation of domination and power relations, and then finally, via Clifford Geertz and Erik Eriksson, to a positive view of ideology as social integration that preserves the identity of groups through practices of mutual recognition (RICOEUR, 1986, p. 266-71). According to Ricoeur, such practices provide the normative medium of articulation for the constitutive links between selves and values (RICOEUR, 1992, p. 121-2), whose distortion leads some individuals and groups to accept or reject norms based on value-orientations they identify as their own even though their needs, whether they realize this or not (and especially when they do not realize it), might be better interpreted by a different set of values and better served by an alternative set of norms. In this interpretation, orientations to value are not implicitly ideological. However, some orientations to value necessarily assume ideological functions as soon as evaluative resources are used to cover up and thus to ignore or reinterpret 
| 146 |

Normative Reconstruction...

needs in ways that secure a strong cultural basis for control over the deliberative arena in which needs are selected - in the form of generalizable interests - for incorporation into (or satisfaction by means of) norms. Only if the exclusive orientation to some values implicitly distorts the choice of generalizable interests and thus the process of selecting appropriate valid norms can we call this orientation ideological and its effects on identity distortive. The task of ideology critique is to expose those latent distortive effects that are typically covered up in the process of the cultural reproduction of social groups. According to Ricoeur, such effects are revealed by the dialectic of two, equally pathological forms of the imagination, ideology and utopia. The pathology of ideology is distortion while the pathology of utopia is escapism (RICOEUR, 1991, p. 251). The dialectic is supposed to test our attraction to the vision of social life and our role within it that each of them provides, that is, the values that structure this life and shape our sense of orientation in it. As two species of the cultural imagination, ideology and utopia engage in a battle of motivations that puts the individuals who are exposed to it in a position to submit to the more powerful of the two in a way that also indicates the perceived superiority of one value over the other. Thus, the winner in the battle of motivations is the value whose superiority could not be asserted in terms of cognitive growth or error reduction alone.

If we were to critique Ricoeur's conception of ideology critique, we would have to point out that it is seriously limited by the fact that it fails to account for any independent epistemic conditions that may entitle agents to match the higher intensity of their attraction to a given value to a particular instance of cognitive growth. Unlike Honneth, Ricoeur pays no attention to the material conditions that make the recognition of a value orientation practical and not merely symbolic. In Ricoeur's portrayal, the dialectic of ideology and utopia is a game played exclusively by the two sides of the imagination, both of which seem utterly detached from the practical conditions of desire satisfaction. The imagination seems to be a form of free-floating reflection on cultural contents that bears no recognizable relation to our conscious or unconscious needs, 
desires, impulses, or drives. However, this connection is essential to understanding the socio-cultural and political relevance of the imagination, and it is in this area that Honneth's theory is demonstrably superior. The link between the imagination (as the representation of a value in the shape of a form of social life) and the interpretation of our need structure in terms of such a value is much more clearly outlined in Honneth's writings. As Honneth argues in his essay on ideology, recognition is distortive as long as it is only symbolic or imaginary, that is, if it cannot match the conditions of satisfaction of the need or desire that it claims to respond to. The power to motivate that is exercised by a symbolic formation of the imagination cannot prevail if it is not backed up by corresponding normative and institutional value instantiations in the real world of social practice (HONNETH, 2008, p. 345). These instantiations are status functions that must conclusively, that is, practically, respond to needs. Needs cannot be indefinitely stifled or sustained by a value orientation that is not firmly anchored in the material conditions of practical life. If such were the case, it would not be long before the imagination would have to retreat to make room for real changes in our need basis.

In this paper, I argued that Honneth's method of normative reconstruction can only be assessed against the evaluative background provided by pre-existing attitudes of recognition. Given that attitudes of recognition are also interpretive practices through which agents affirm, validate, and pursue their value orientations, it follows that normative reconstruction can also be regarded as a higher-level form of interpretive practice that works by verifying the motivational power of our orienting values, the expressive capacity of practical norms with respect to these values, and the functional adequacy of social institutions in relation to their guiding norms. In the last part of the paper I compared Honneth's method to two alternative approaches that are also deeply indebted to hermeneutical philosophy: Charles Taylor's theory of practical reasoning and Paul Ricoeur's conception of ideology critique. Normative reconstruction is similar to these approaches in some respects - it presents normative change as a form of cognitive 
| 148 |

Normative Reconstruction...

growth and the critique of values in terms of interpretations that weaken their motivational power -, but it is also very different in other respects, namely, Honneth's account of normative change is more radical and far-reaching than Taylor's and his critique of values is more empirically grounded than Ricoeur's.

\section{References}

BERNSTEIN, R. J. Beyond Objectivism and Relativism: Science, Hermeneutics, and Praxis. Philadelphia: University of Pennsylvania Press, 1983.

BRANDOM, R. B. The Structure of Desire and Recognition: Self-consciousness and Self-constitution. Philosophy and Social Criticism, v. 33, n. 1, p. 127-50, 2007.

GADAMER, H.-G. Truth and Method. Transl. J. Weinsheimer and D. G. Marshall. New York: Crossroad, 1989.

HEIDEGGER, M. Being and Time. Transl. J. Stambaugh. Albany: SUNY Press, 2010.

HONNETH, A. Recognition as Ideology. In: v. d. BRINK, B; OWEN, D. (eds.). Recognition and Power: Axel Honneth and the Tradition of Critical Social Theory. Cambridge: Cambridge University Press, 2008, p. 323-47.

A Physiognomy of the Capitalist Form of Life. In: Pathologies of Reason. Transl. James Ingram and others. New York: Columbia University Press, 2009.

Freedom's Right: The Social Foundations of Democratic Life. Transl. Joseph Ganahl. New York: Columbia University Press, 2014a.

The Normativity of Ethical Life. Transl. Felix Koch. Philosophy and Social Criticism, v. 40, n. 8, p. 817-26, 2014b. 
Rejoinder. Transl. Owen Hullat. Critical Horizons, vol. 16, n. 2, p. 204-26, 2015.

RICOEUR, P. Lectures on Ideology and Utopia, ed. George H. Taylor. New York: Columbia University Press, 1986.

From Text to Action: Essays in Hermeneutics, II. Transl. Kathleen Blamey and John B. Thompson. Evanston, Ill.: Northwestern University Press, 1991.

Oneself as Another. Transl. Kathleen Blamey. Chicago: The University of Chicago Press, 1992.

RORTY, R. Consequences of Pragmatism: Essays: 1972-1980. Minneapolis: University of Minnesota Press, 1982.

TAYLOR, C. Explanation and Practical Reasoning. In:Philosophical Arguments. Cambridge, Mass.: Harvard University Press, 1995, p. 34-60. 